\title{
A FACE DO TECIDO URBANO E AS MAZELAS AO ACESSO À MORADIA SOCIAL: COMO O CASO DO MUNICÍPIO DE PETRÓPOLIS DESVENDA A CONSTRUÇÃO DE UMA LENDA URBANA
}

\section{THE FACE OF URBAN TISSUE AND THE MALADIES REGARDING TO THE ACCESS OF SOCIAL HOUSING: AS IN THE CASE OF PETROPOLIS MUNICIPALITY UNVEILS A CONTRSTRUCTION OF A URBAN LEGEND.}

\author{
Carmem Matos ${ }^{1}$ \\ ${ }^{1}$ Universidade do Estado do Rio de Janeiro (UERJ), Rio de Janeiro,RJ, Brasil
}

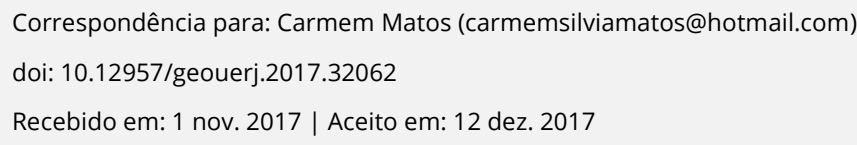

\section{RESUMO}

A política habitacional de interesse social tem sofrido as limitações impostas pelo tratamento da terra urbana como um capital a ser valorizado. Essa abordagem empresarial está subjacente ao Programa Minha Casa Minha Vida e tem contribuído para intensificar a periferização das cidades, sob o argumento da escassez de terras nas áreas centrais, dotadas de infraestrutura urbana. Este artigo coloca em xeque esse argumento com base num estudo tomando como referência parte da área central do município de Petrópolis (RJ), onde foram identificados imóveis ociosos suficientes para serem edificados e, assim, atender $60 \%$ do déficit habitacional naquele território. A partir disto, sinaliza-se a necessidade de atuação do poder municipal para que conheça profundamente o próprio tecido urbano por meio de um cadastro multifinalitário que respalde o planejamento da política habitacional e inclua na sua base de dados os imóveis que não cumprem com a função social da propriedade.

Palavras-chave: Política habitacional. Moradia social. Gestão municipal do território urbano.

\section{ABSTRACT}

Social interest housing policy have suffered the limitations imposed by the management of urban soil as a commodity. This entrepreneurial approach is behind Minha Casa Minha Vida Program and has contributed to the peripherization of cities, under the argument of lack of available land in central areas, endowed with urban infrastructure. This article puts in check this argument, with basis on a study taking as reference part of the central area of the municipality of Petrópolis (RJ), where idle estates were identified for building edification, in a number sufficient to attend $60 \%$ of the local housing deficit. From this, it is signalized to the municipality, the need of deeply acknowledging its own urban tissue by means of a multi aspect record that supports the planning of housing policy and includes in its database the properties that do not fulfill its social role.

Keywords: Housing policy. Social housing. Municipal management of urban land.

\section{INTRODUÇÃO}

O Estatuto da Cidade (Lei 10.257/01) ao estabelecer seus princípios e diretrizes identifica a cidade como um bem coletivo, e ainda que os vários aspectos do exercício do direito de propriedade (domínio, apropriação, uso do solo, disposição) só são legítimos quando cumprem com a sua função social. Logo, cidade, coletividade e função social entrelaçam-se mutuamente formando um bem coletivo abrangente constituído por serviços públicos, infraestrutura, moradia, relações sociais e econômicas, que existe, principalmente, para acolher pessoas. 
A cidade, portanto, resulta da produção e interação destes bens materiais e imateriais conferindo um espaço multifuncional muito valorizado por seus moradores, e estes por sua vez anseiam em usufruir deste dinamismo de forma igualitária e justa. Sendo assim, o uso do solo urbano deve vincular-se a uma regulação que resista a possibilidade de tratar a terra como uma mercadoria, já que desta depende o direito à moradia, base fundamental da dignidade humana e direito social expresso na Constituição Federal.

De acordo com a Constituição e o Estatuto da Cidade (Lei 10.257/01), o imóvel que não cumpre a sua função social é aquele ocioso em razão de subutilização ou não utilização/edificação. Portanto, torna-se necessário definir critérios para a identificação da ociosidade, determinando se um imóvel está ou não inserido na função social da cidade.

A gestão do território urbano, portanto, deve pautar-se no controle do uso da terra em benefício de toda a coletividade, visando incluir uma grande parcela da população de baixa renda que não consegue aceder às áreas servidas de melhor infraestrutura urbana. Esse controle é possível a partir do manejo coerente e articulado dos instrumentos urbanísticos disponíveis, valorizando, por exemplo, a aplicação do IPTU progressivo no tempo e a arrecadação de imóvel por abandono do proprietário.

Neste artigo, vamos tratar da importância do cadastro imobiliário não ser visto apenas para fins de arrecadação tributária, mas sim como instrumento essencial ao conhecimento e planejamento do território urbano. Trata-se de uma condição preliminar à atuação das prefeituras na política habitacional, possibilitando a identificação dos imóveis que não estejam cumprindo sua função social.

Esclarece-se, por oportuno, que a gestão do território, neste estudo, está focada no planejamento do direito à moradia a partir de um mapeamento completo do tecido urbano com o objetivo de oferecer soluções viáveis à diminuição do déficit habitacional. A construção de um cadastro com base de dados ampla e diversificada permite que o planejamento habitacional seja integrado ao conhecimento do território, e com isso, as áreas centrais, mais valorizadas em razão de sua infraestrutura e de seus serviços essenciais, seriam aproveitadas pela produção de habitação social favorecendo às camadas 
mais vulneráveis da população que alcançariam moradia em locais dotados com melhores equipamentos públicos.

Tal mapeamento, além de integrar o conhecimento territorial ao planejamento habitacional, pode promover alternativas de planejamento urbano mais adequadas a realidade local uma vez que identifica espaços pertinentes a toda a dinâmica social, oferecendo um contexto mais rico e diversificado a partir do estudo da cidade.

Essa dinâmica personalizada permite romper o formato único de produção de habitação social estabelecido pelo Programa Minha Casa Minha Vida (PMCMV), baseado na construção de grandes condomínios nas periferias das cidades nos moldes do antigo BNH.

O mapeamento do tecido urbano torna-se um instrumento necessário ao enfrentamento do déficit habitacional uma vez que instrumentaliza novas alternativas em contraponto à opção imposta pelo mercado imobiliário. Esse instrumento de planejamento urbano ao ser manejado contribui com a possibilidade de o poder municipal resgatar a planificação habitacional às suas mãos e retirando do mercado a exclusividade de atuação. Essa retomada de poder leva a um controle do uso do solo mais vinculado ao interesse social do que ao lucro de mercado, rompendo com a mercantilização da terra urbana e planejando o seu uso a partir do próprio potencial.

O poder público ao omitir-se em relação ao planejamento do tecido urbano deixa-o ao arbítrio das construtoras que atuam no mercado imobiliário. Esta inversão de funções levou o mercado a tratar a produção de moradia social como um grande nicho de mercado, e por consequência as empresas do ramo passaram a protagonizar a política habitacional por meio do PMCMV, controlando a sua produção, a terra urbana, o financiamento e quem se beneficia (SCHIMBO, 2010).

Entretanto, a responsabilidade pela política urbana é do município, ainda que a União formule e financie a política habitacional (BONDUKI, 2009). Sendo assim, mesmo aderindo ao PMCMV, cabe ao poder municipal atuar de acordo com sua competência, isto significa que deve protagonizar o 
planejamento habitacional atuando em diversas frentes, como, por exemplo, indicando imóveis aptos à produção de moradia em áreas mais centrais e infraestruturadas, elaborando projetos adaptados às condições do seu território em contraponto aqueles de cunho mercantil e formato padrão, e envolvendo as comunidades nas escolhas e discussões a fim de desenvolver um planejamento legítimo e coerente com o interesse local.

A legitimidade de planejamento perpassa pela identificação de imóveis ociosos ou sub-utilizados como fonte de potencial fundiário fundamental na construção da política de moradia social, estes representam elementos freqüentes no tecido urbano, que muitas vezes servem como instrumento de especulação imobiliária, ou, simplesmente, retratam bens destituídos de função social, portanto, não aproveitados pelo planejamento urbano.

Nesse sentido, se é do município a responsabilidade pela política urbana, a esse cabe instrumentalizar a política de habitação com o conhecimento do seu território incluindo nesta perspectiva os imóveis ociosos que o compõem.

Neste estudo procuramos explorar essa possibilidade por meio de um estudo de caso, tomando o município de Petrópolis, no Estado do Rio de Janeiro, como referência. O artigo está composto desta introdução como o primeiro capítulo. No segundo, traçamos um breve perfil do Município de Petrópolis, destacando a sua normativa em relação à política habitacional. No terceiro, apresentamos um estudo de caso onde foram levantados os imóveis ociosos em três bairros do Primeiro Distrito, a área central do Município. Finalmente, no quarto, apresentamos algumas considerações à guisa de conclusão.

\section{Cadastro territorial: instrumento fundamental à gestão social do município}

Os primeiros cadastros elaborados pela administração pública foram estruturados para equacionar o sistema de tributação. As bases de composição do denominado Cadastro Econômico registravam o valor da parcela e essa era utilizada para o cálculo do imposto territorial. 
A maioria dos cadastros implementados atualmente, nos diferentes níveis de governo, ainda seguem esse mesmo objetivo. Entretanto, a necessidade de novos métodos de avaliação, baseada em detalhes mais construtivos, exige que as bases de dados sejam ampliadas para refletir a realidade da ocupação do solo urbano. Tais ampliações se referem à identificação da localização, forma, dimensões e, principalmente, a funcionalidade dos imóveis urbanos. Este mapeamento multifinalitário serve de instrumento apto a incrementar a valorização social da terra e o planejamento municipal de habitação, uma vez que fornece dados precisos para viabilizar a implantação de instrumentos urbanísticos (ERBA, 2005).

O Cadastro possui duas dimensões funcionais: positiva, quando protege o direto de propriedade mediante a publicidade imobiliária; e negativa, quando restringe o poder de livre disposição do bem pelo titular em benefício do interesse público.

Portanto, é um instrumento capaz de contribuir com o cumprimento da função social da propriedade, assumindo o papel de polícia territorial com o poder de fiscalizar a funcionalidade dos imóveis que compõem o tecido urbano.

A tendência de elaborar cadastros com o fim de conhecer a cidade e as possibilidades de aprimorar o planejamento do espaço urbano não é tão recente. Recebeu muito incentivo a partir de junho de 1996 , com a Segunda Conferência das Nações Unidas sobre Assentamentos Humanos (HÁBITAT II), que reafirmou a necessidade de administrar corretamente o território para promover a segurança da moradia e acelerar os processos de desenvolvimento (ERBA, 2005).

Com isso, se fortalece a necessidade de inserir o cadastro no planejamento e desenvolvimento contemporâneo das cidades, principalmente para a promoção da moradia social. A função do cadastro tornou-se tão fundamental para o correto planejamento do espaço, que a sua ampliação foi determinada no sentido de incluir as informações ambientais e sociais às bases de dados econômicos, físicos e jurídicos. 
Esse processo, que começou a ser esboçado no final da Segunda Guerra Mundial, consolidou-se posteriormente na nova visão de Cadastro Territorial Multifinalitário (CTM).

O sistema de elaboração de cadastro iniciou-se com uma visão puramente fiscal. Esse sistema não delimita o direito de propriedade de cada parcela (menor unidade de registro) com precisão nem consegue identificar se o imóvel está efetivamente funcional. Também não mostra as limitações impostas pelas normas de planejamento, tais como: servidões administrativas, desapropriações, parcelamentos e edificações compulsórios.

Diante das falhas constatadas, tornou-se necessária a criação de um novo sistema de cadastro que trouxesse as informações de forma mais ampla e integrada.

Em 2007, foi criado um grupo de estudos (GT-Cadastro) (BRASIL, 2007), ${ }^{1}$ para estudar a matéria e formular uma proposta de diretrizes compatível com a realidade diversificada dos municípios brasileiros, o que resultou em portaria ${ }^{2}$ ministerial de caráter orientador (BRASIL,2009), que estabeleceu as diretrizes para a criação e atualização do Cadastro Territorial Multifinalitário (CTM) pelos municípios.

Esse sistema torna mais amplo o registro de dados no cadastro e o transforma em um inventário público metodicamente ordenado de todos os objetos territoriais legais de determinado país ou distrito, tomando como base a mensuração dos seus limites. Tais objetos legais identificam-se sistematicamente por meio de alguma designação, e a delimitação da propriedade e o identificador, junto à informação descritiva, podem mostrar, para cada objeto territorial, sua natureza, o tamanho, o valor e os direitos e, ou, restrições legais associadas a ele (ERBA, 2005).

O novo sistema cadastral compreende desde as medições, que representam toda a parte cartográfica, até a avaliação socioeconômica da população. Pretende mostrar a situação legal do território de forma

\footnotetext{
${ }^{1}$ Portaria № 516, de 16/10/2007, publicada no DOU de 17/10/2007

${ }^{2}$ Portaria Ministerial № 511, de 07 de dezembro de 2009, que institui Diretrizes para a Criação, Instituição e Atualização do Cadastro Territorial Multifinalitário (CTM) nos Municípios Brasileiros, DOU de 08 de dezembro de 2009.
} 
completa, incluindo o direito público e as restrições, substituindo a cartografia tradicional pela modelagem cartográfica e digitalizando todo o sistema de informação.

Os aspectos considerados pelo CTM são: econômicos (variáveis que levam a determinar o valor do imóvel e do imposto), geométricos (como a localização, forma e dimensões da parcela), jurídicos (que determinam a relação homem-parcela), sociais (que permitem delinear o perfil do proprietário ou possuidor) e ambientais.

Além desses fatores práticos, pretende viabilizar uma grande participação do setor privado, podendo até mesmo ocorrer a privatização total do cadastro com a consequente venda de dados a usuários e a possibilidade de reinvestimento e atualização na melhoria do sistema.

Essa forma técnica de conhecer o ambiente da cidade trará informações precisas e fundamentais para a gestão territorial como um todo. Mas, precisamente, no que se refere ao planejamento de habitação social, o cadastro conterá elementos indispensáveis que permitirão definir a melhor forma de aproveitar o tecido urbano já estruturado, contribuindo com a indicação dos imóveis ociosos. Sendo assim, o cadastro relaciona a realidade local com a possibilidade prática de implementação dos institutos do Estatuto da Cidade, funcionando como um liame entre o direito posto e a efetividade da lei.

Na medida em que os instrumentos urbanísticos forem sendo aplicados de acordo com os elementos indicados no cadastro, esses mesmos instrumentos farão parte do cadastro com as novas atualizações. Estas, por sua vez, continuarão gerando o acompanhamento e fiscalização dos gravames e, por consequência, a funcionalidade dos imóveis.

Esse percurso cadastro/política-pública seria o resultado ideal da articulação entre os instrumentos. Dito dessa forma, parece que todo esse arcabouço legal e prático soa como uma utopia urbana sustentada pelas perspectivas propostas. Entretanto, sinaliza-se que não é legítimo abdicar de projetos transformadores nem nos contentarmos em "fazer aquilo que é possível”. Este jargão pode significar a 
reprodução do status quo alimentado pelas mesmas e perversas dinâmicas e relações que dominam nossas cidades. A defesa de mudanças profundas está na ordem do dia. Transferir parte da produção e planejamento de habitação social para o poder público municipal implica no enfrentamento do crescente déficit habitacional, retirando, de forma coerente, o protagonismo do setor da construção ao redirecioná-lo a valorização fundiária no rumo da função social.

Essa necessidade de transferência designa uma política de freios e contrapesos no sentido de o Estado oferecer um movimento de resistência alternativo e contrário à padronização da produção de moradia. Afinal, o domínio de um determinado sistema empobrece o alcance social e a diversidade de resultados que as ações e programas governamentais são capazes de atingir.

Trata-se de requalificar o poder público como o termômetro social, equilibrando a atividade econômica e a justiça social, não permitindo que um seja diminuído pelo outro. Tal como a luta para retirar a cidade do controle dos especialistas e eliminar o monopólio tecnocrático sobre a cidade. Em outras palavras, a luta para democratizar a cidade e inserir um olhar mais sensível e humano, edificando os valores comunitários, históricos, culturais e as demais conquistas sociais.

Mais uma vez lembrando o pensamento de Lefebvre (2013), na sua obra Direito à Cidade, onde afirma que os problemas urbanos não podem ser resolvidos apenas na prancheta do arquiteto: há que existir um entrelaçamento de direitos e interesses diversos vindos dos vários segmentos sociais, para que todos sejam lembrados, e, assim, garantir que a noção de sistema não "engula" a noção de estratégia, a que melhor representa essa diversidade.

A Utilização do Cadastro Territorial Multifinalitário como Instrumento de Democracia e Controle Social.

Seguindo o encadeamento lógico de traçar estratégias a fim de garantir uma cidade para todos, passaremos a examinar a questão do conhecimento detalhado do tecido urbano como requisito essencial ao planejamento urbano e habitacional. 
Dessa forma, já identificamos o Cadastro territorial Multifinalitário (CTM) como um instrumento fundamental à Administração Pública, no exercício da sua governabilidade. Representa um recurso necessário à implementação de políticas públicas em razão da reserva de dados diversificada e integrada.

O levantamento cadastral aperfeiçoa a realização do planejamento municipal e proporciona mais transparência administrativa e fiscal para a população. Como exemplo, destaca-se o caso de Belém, amplamente discutido por Georgina Galvão e Mauro Gaia (2005), e cujas informações e dados passase a descrever nas linhas abaixo.

Os autores descrevem o baixo desempenho da administração de Belém, que não se servia de nenhum mecanismo de integração entre os cadastros, utilizava informações e modelos desatualizados e atuava com dados insuficientes para a elaboração de estratégias capazes de orientar a ação fiscalizadora e o correto lançamento dos tributos.

Relatam ainda que, em anos anteriores, houve uma tentativa desastrosa de recadastramento, cujas maiores consequências foram o lançamento de inscrições em duplicidade e uma significativa concentração de erros no setor fiscal de maior densidade populacional de Belém.

O passo mais importante para a mudança estrutural da gestão municipal foi a implantação do CTM, que envolveu vários órgãos da administração, tanto para a definição do programa de necessidades quanto para a execução e acompanhamento do mesmo.

A partir de então, foi observado o aumento da arrecadação e de isenções fiscais, e o CTM se inseriu como instrumento de referência para viabilizar a implementação de políticas públicas nas mais diversas áreas de atuação, tais como: intervenções no sistema viário, drenagem, pavimentação, iluminação pública, sinalização viária, projetos de revitalização de áreas degradadas e de moradia. 
A sua aplicação trouxe, como principal elemento de inovação, o rompimento com a lógica tradicional adotada na elaboração de cadastros municipais que possuem um viés desarticulado e limitado de informações. Em contraste, o CTM produziu a universalidade de seu alcance e a elevação da base de dados, que foi alterada de 220.000 para 360.000 inscrições imobiliárias, perfazendo um aumento em torno de $61 \%$ em relação ao cadastro anterior.

O cadastramento dos imóveis foi realizado com foco nas múltiplas potencialidades apontadas à gestão municipal e não apenas no interesse fiscal. Dessa forma, foram cadastradas tanto as áreas valorizadas quanto os assentamentos populares sem infraestrutura, tradicionalmente desconsiderados pelas empresas de aerofotogrametria e levantamento cadastral, que costumam representá-los no mapa por meio de manchas com a denominação de favela.

A partir da decisão política de cadastrar todos os imóveis localizados na área urbana do Município, afastando o interesse meramente arrecadatório, foi necessário realizar um estudo de redistribuição fiscal, a fim de equilibrar a carga tributária no sentido de desonerar os ônus tributários incidentes sobre os imóveis urbanos que cumprem sua função social, bem como de reconhecer a isenção daquelas propriedades residenciais de baixo valor patrimonial para o mercado imobiliário.

Com os primeiros resultados obtidos pela implantação do cadastro multifinalitário, foi possível, através da Lei nº 7.986 de 30/12/1999, ampliar para 9.000 UFIR (equivalente a $\mathrm{R} \$ 9.576,90$ ) o limite da isenção automática. Esta medida permitiu, já no lançamento do IPTU 2000, elevar para 84.264 o número de contribuintes isentos que até 1999 somavam apenas 16.173 (em torno de $7 \%$ do total cadastrado). Isto foi conseguido sem que houvesse redução na arrecadação, ou seja, o aumento do número de imóveis cadastrados, bem como a atualização das benfeitorias dos imóveis anteriormente cadastrados, compensou a ampliação do universo de imóveis beneficiados pela isenção automática (GALVÃO; GAIA, 2005, p.123).

A redistribuição da carga tributária alcançada com a conclusão do cadastro Multifinalitário permitiu o aumento nominal do limite de isenção, elevando para 49\% o número de contribuintes isentos no novo 
cadastro, e uma elevação na arrecadação do IPTU junto com taxas agregadas em $\mathrm{R} \$ 22,6$ milhões, em 1996, para $\mathrm{R} \$ 39,0$ milhões, em 2003, mesmo com 179 mil imóveis isentos, em um total de 360 mil imóveis. Para poder cobrar o IPTU levando em consideração a capacidade contributiva dos cidadãos, tornou-se absolutamente imprescindível ter uma base cadastral confiável dos imóveis (GALVÃO; GAIA, 2005).

O novo cadastro possibilitou, ainda, que as áreas da cidade, que historicamente sempre receberam maior aporte de investimentos, passassem a participar com uma contrapartida maior e mais condizente com os benefícios recebidos: afinal podem suportar alíquotas superiores. Em contrapartida, áreas que anteriormente foram muito valorizadas, e que passavam por processos de degradação, quase sempre resultantes de modelos de urbanização inadequados, tivessem seus valores ajustados à nova realidade. É importante destacar que o crescimento das receitas municipais não se deu por aumento no valor dos tributos, mas pela aplicação de uma POLÍTICA DE JUSTIÇA FISCAL, exigindo-se tributos de quem pode pagar, isentando quem não tem capacidade contributiva, corrigindo bases de cálculos, sem, contudo aumentar o valor das alíquotas (GALVÃO; GAIA, 2005, p. 128).

A partir do mapeamento multifinalitário o município poderá protagonizar o desenvolvimento e crescimento da cidade, sem se tornar refém do mercado de construção, que se antecipa em determinar para onde a cidade deve crescer, produzindo o espaço urbano de acordo com seus empreendimentos e interesses de lucro.

Essa dinâmica do setor privado traça previamente o seu planejamento de execução, realizando vários estratagemas de ação, tais como: investir especulativamente no mercado imobiliário, adquirindo um "banco de terras" para o futuro; formando aliados políticos, por meio do financiamento privado de campanhas; participando da elaboração de programas governamentais.

Esse encadeamento de atos perpetrados pela iniciativa privada assume o papel de plano de investimento do empresariado. Da mesma forma, cabe ao poder municipal a tarefa de planejar suas ações futuras conhecendo o próprio terreno de ação por meio do mapeamento urbano, tornando 
possível detectar a melhor forma de aproveitamento do tecido urbano para a implementação de instrumentos urbanísticos de gestão social e crescimento da arrecadação.

A aplicação desses instrumentos somados a uma efetiva tributação pode contribuir para o aumento do recurso público vinculado ao financiamento de habitação e melhoria de serviços e infraestrutura, gerando com isso uma maior autonomia do município. Atualmente, o mercado de construção detém o protagonismo da produção de moradia em razão da própria construção da Lei 11.977/09 que dispõe sobre o programa Minha Casa Minha Vida, uma vez que, permite a hegemonia do mercado na corrida das contratações.

Logo, o empreendedorismo privado prevalece-se da permissão legal e operacionaliza uma oportunidade de alto lucro e pouco risco. Entretanto, cabe salientar que essa hegemonia privada acontece porque não depara-se com uma resistência contrária suficientemente forte para direcionar e controlar essa produção de espaço urbano. O domínio de mercado leva a uma precarização de resultados (baixa qualidade, periferização, capitalização da moradia, ausência de infraestrutura, exclusão de cidadania) e maximização de lucros em decorrência da ausência de alternativas concretas.

Diante desse quadro, cabe ao poder público entrar nessa produção diretamente ou por meio de mecanismos jurídicos e urbanísticos de planejamento, com o fim de interferir incisivamente no direcionamento do crescimento da cidade e seu desenvolvimento social. Se a resposta ao déficit habitacional restar exclusivamente nas mãos do mercado, que visa somente ao lucro, cai por terra a ideologia constitucional da função social e todas as suas conquistas.

Ressalta-se, ainda, que o direcionamento da política urbana pode influenciar na diminuição da alta dependência de recursos advindos das transferências de outros níveis governamentais. É uma situação que fragiliza a autonomia dos municípios e estimula os administradores a desempenharem um papel passivo diante das dificuldades financeiras, aguardando por uma política nacional para a resolução dos problemas enfrentados em nível local. 
Ao observar o "passo a passo" para a reestruturação da habitação social, percebe-se que esta deve ser iniciada pelos imóveis ociosos que compõem o tecido urbano já infraestruturado. Para tanto, o governo deve encarar seu papel de titular da política urbana e trabalhar em conjunto com os diversos atores sociais, buscando o equilíbrio de interesses e a harmonia de resultados, de forma a não submeter o direito à moradia ao lucro de mercado.

\section{Imóveis ociosos: o município de Petrópolis como caso de referência}

Este artigo explora os resultados de uma pesquisa de campo realizada na cidade de Petrópolis, Região Serrana do Rio de Janeiro, com o objetivo de utilizá-la como caso de referência neste estudo. A pesquisa estabelece um parâmetro exemplificativo que possibilite demonstrar, de forma prática, a incoerência provocada pelo desconhecimento do tecido urbano da política habitacional.

Apesar da enorme importância de todos os tipos de ociosidade imobiliária apresentada no tecido urbano das cidades, a pesquisa limita-se à identificação de terrenos vagos (não construídos) nos referidos bairros centrais. Esta escolha explica-se em função da grande dificuldade em identificar o não uso ou a subutilização sem o auxílio do poder público.

\section{O Município de Petrópolis (RJ)}

A cidade de Petrópolis desenvolveu-se a partir da exploração da atividade industrial chegando a implementar o mais importante polo têxtil do país, onde foram instaladas as fábricas: Imperial Fábrica de São Pedro de Alcântara, Companhia Petropolitana, Aurora, Werner, Santa Helena, Dona Isabel e a Cometa.

No final do século XIX, possuía cerca de vinte e nove mil habitantes atingindo o ápice de trinta e cinco mil no verão. Desde a sua fundação até os dias de hoje, manteve as características de abrigar casas de segunda residência das camadas média e alta rendas da sociedade carioca, constituindo-se também em um intenso polo turístico, que gerou uma forte ligação com o Rio de Janeiro (PETRÓPOLIS, 2012). 
Na década de 1960, inicia-se o processo de perda das indústrias e a migração de investimentos do setor têxtil para a cidade de São Paulo e para a Região Nordeste, em especial Paraíba e Bahia. Com isto, esvazia-se a principal atividade econômica do município, com a Indústria sendo substituída pelas atividades de Comércio e Serviços, atuais motores da economia petropolitana. Ainda que tenha perdido dinamismo, a população atingiu 295.917 habitantes, de acordo com o Censo Demográfico de 2010, parte da qual enfrenta dificuldades para ter acesso ao direito constitucional à moradia.

\begin{tabular}{ll}
\hline DISTRITO (\%) & POPULAÇÃO \\
\hline Petrópolis $(63 \%)$ & 185.876 \\
Cascatinha $(23 \%)$ & 64.936 \\
Itaipava ( 7\%) & 20.444 \\
Pedro do Rio (5\%) & 14.079 \\
Posse $\quad(3 \%)$ & 10.582 \\
\hline TOTAL & 295.917 \\
\hline
\end{tabular}

Tabela 1. Distribuição da população nos distritos do Município de Petrópolis, 2010. Fonte: Prefeitura Municipal de Petrópolis, 2011, com base no Censo IBGE, 2010.

O Município integrou a Região Metropolitana do Rio de Janeiro desde a época de sua criação (1974) até 1993, momento em que foi integrado à Região Serrana pela nova divisão de Regiões de Governo do Estado. Sua extensão territorial abrange $795,8 \mathrm{~km}^{2}$, contando com uma população total de 295.917 habitantes, sendo 95\% urbana, e densidade demográfica de 371,85hab/km² (IBGE, 2010). É composto por cinco distritos: Petrópolis $\left(1^{\circ}\right)$, Cascatinha $\left(2^{\circ}\right)$, Itaipava $\left(3^{\circ}\right)$, Pedro do Rio $\left(4^{\circ}\right)$ e Posse $\left(5^{\circ}\right)$. A maior parte da população $(63 \%)$ está concentrada no distrito de Petrópolis, que detém o maior volume de atividades econômicas, empregos, equipamentos públicos, infraestrutura e serviços, representando a área mais consolidada e de ocupação mais antiga.

\section{Desafios da política habitacional em Petrópolis}


Em 2012, o Município de Petrópolis apresentou um déficit quantitativo habitacional acumulado de 11.828 moradias, sendo 5.213 em assentamentos precários e 6.616 fora destes ${ }^{3}$. Segundo o seu Plano Local de Habitação de Interesse Social (PLHIS), elaborado no mesmo ano, estimou-se uma inadequação habitacional (qualitativa) de 21.395 domicílios com algum tipo de carência ligada a infraestrutura ou regularização fundiária, e ainda 11.568 residências classificadas como unidades de Risco Alto ou Muito Alto, em relação ao escorregamento de encostas (PETRÓPOLIS, 2012).

\begin{tabular}{lc}
\hline DOMICÍLIOS & TOTAL \\
\hline Déficit habitacional quantitativo em & 5.213 \\
assentamentos precários & 6.615 \\
Déficit habitacional quantitativo fora & \\
de assentamentos precários & 21.395 \\
Inadequação habitacional qualitativa & \\
em assentamentos precários & 33.223 \\
\hline TOTAL
\end{tabular}

Tabela 2. Resumo do déficit habitacional dentro e fora de assentamentos precários. Fonte: PLHIS do Município de Petrópolis, com base na elaboração de DEMACAMP. Planejamento, Projeto e Consultoria Ltda. 2012.

A situação de risco surge em razão de a cidade ter sido construída entre montanhas que apresentam um alto índice de risco geológico por condicionantes naturais, e ainda pela densa ocupação de suas encostas após a década de 1950. Esta soma de fatores transforma parte do território urbano em uma grande área de situação de risco, principalmente, aquela compreendida pelo Primeiro Distrito, local que concentra a maior parte da população (63\%), cujo relevo é mais acidentado. Em que pesem as peculiaridades descritas, essa área abriga no seu tecido urbano seis favelas, classificadas como não consolidáveis, em razão do risco de desabamento das encostas, contabilizando 2.786 habitações em risco muito alto e 4.290 em risco alto, apresentando os piores níveis de risco do município (PETRÓPOLIS, 2012, p. 129 e 130).

\footnotetext{
${ }^{3}$ Plano Local de Habitação Social de Petrópolis. 2012, p. 138, 144 e 145.
} 
O Plano Local de Habitação de Interesse Social (PLHIS) define uma demanda de terra de $362.625 \mathrm{~m}^{2}$ para combater o déficit de 2.994 moradias (PETRÓPOLIS, 2012, p. 153) dentro dos assentamentos precários do Primeiro Distrito. Acontece que as moradias em situação de risco situadas naquela área, segundo os dados acima apresentados, somam 7.076 residências, restando, portanto, um saldo de 4.082 moradias em risco sem respaldo no planejamento municipal.

A partir dos dados apresentados acima, percebe-se que a maioria dos imóveis em situação de risco não consta no planejamento de habitação do Município. Da mesma forma, não consta no PLHIS o manejo de imóveis ociosos, ou ao menos a identificação destes, para compor a política habitacional. Com isso, retira a possibilidade de incluir um importante potencial fundiário da cidade para contemplar a promoção de moradia social. Cabe salientar a existência de imóveis ociosos em áreas centrais do Primeiro Distrito, contando com infraestrutura e serviços públicos sedimentados, como adiante será demonstrado.

Parece claro que um dos elementos fundamentais para a produção de Habitação de Interesse Social é a disponibilidade de terra urbana apta a receber os empreendimentos. O PLHIS de Petrópolis define "terras aptas" como os terrenos bem localizados na cidade que possuam boa acessibilidade e suficientes equipamentos públicos para servir à população moradora. Além disso, devem apresentar uma infraestrutura urbana compatível com o adensamento que será provocado pelos novos empreendimentos habitacionais.

Observa-se que o déficit de moradia é uma questão urbana complexa que deve ser enfrentado com a utilização de todos os recursos locais possíveis, mas, apesar disto, o PLHIS não inclui a identificação dos imóveis ociosos como mais um mecanismo apto a compor a política habitacional. Para aproveitar o potencial fundiário do seu tecido urbano, o caminho a ser percorrido pelo poder público é a implementação de um cadastro territorial que permita a identificação dos vários tipos de imóveis ociosos que compõem o território do Município. Esta identificação facilitaria a articulação de formas personalizadas de produção do espaço urbano mais adaptadas às condições e características locais, isso 
contribuindo para romper com o padrão único de moradia oferecido pelo mercado e a autoconstrução desordenada das áreas urbanas.

Não é essa a experiência da política habitacional no Brasil. Nas palavras de Raquel Rolnik para o Jornal Folha de São Paulo em publicação de 05.10.2015.

$\mathrm{Na}$ arquitetura das edificações predominam os "puxadinhos" ou os "edifícios-carimbo", reproduzidos ad infinitum, independentemente do lugar e do clima onde estão inseridos. São, de um lado, casas e comércios construídos pelos próprios moradores, de outro, no setor privado e nos programas governamentais de habitação, são projetos elaborados não sob a lógica da qualidade arquitetônica, mas da garantia da rentabilidade do negócio frente aos valores subsidiados pelos programas e os limites de renda dos compradores.

Petrópolis revela a realidade presente em grande parte dos municípios brasileiros, isto é, uma gestão municipal que desconhece o próprio tecido urbano ao planejar sua política habitacional, e, com isso, parte de diagnósticos incompletos para executar um planejamento habitacional que frequentemente está desvinculado das condições locais da cidade. Esta dinâmica contraria o sentido da Portaria 511/09 do Ministério das Cidades que instituiudiretrizes para a criação, instituição e atualização do Cadastro Territorial Multifinalitário (CTM) nos municípios brasileiros ${ }^{4}$ como instrumento útil à gestão pública municipal.

Como já referido, a cidade de Petrópolis possui um relevo acidentado com diferentes situações topográficas e movimentos de terra que tornam a maior parte de seu território inadequado à construção de grandes conjuntos habitacionais. Estes demandam uma paisagem uniforme, de pouca diversidade, bem diferentes da realidade territorial petropolitana, que impõe a técnica de projetos

\footnotetext{
${ }^{4}$ Art. 32. A adoção de um Cadastro Territorial Multifinalitário completo e atualizado auxiliará os Municípios brasileiros a exercerem suas competências prescritas nos artigos 30 e 156 da Constituição Federal de 1988, cumprindo a função social do seu território, prevista no texto constitucional, artigos $5^{\circ}$, inciso XXIII, $3^{\circ}$, incisos I a IV, 30, inciso VIII, 170, inciso III, 182 e 183, atendendo ao princípio da igualdade, nos termos dos arts. $5^{\circ}$, caput e 150, inciso II da Constituição Federal de 1988.

Art. 340 Sistema de Informações Territoriais destina-se a fornecer as informações necessárias para a utilização dos instrumentos da política urbana previstos no art. $4^{\circ}$ da Lei 10.257, de 10 de julho de 2001 - Estatuto da Cidade. Art. 37 A existência de um Cadastro Territorial Multifinalitário atende às Diretrizes Gerais de Política Nacional de Desenvolvimento Urbano, Diretriz No - 125 e Resoluções da $2^{\text {a }}$ e da $3^{\text {a }}$ Conferência Nacional das Cidades, instrumentalizando a construção de um "Sistema Nacional de Política Urbana", por meio das quatro vertentes: planejamento territorial; habitação; saneamento ambiental; trânsito, transporte e mobilidade urbana, com controle e participação social.
} 
desenvolvidos especificamente para o aproveitamento do seu relevo. Com isso, observa-se uma relação de virtual impossibilidade entre a reprodução da lógica de construção de grandes condomínios e a escassez de terra adequada a este padrão que o Município oferece.

Frequentemente, o Município sofre com desabamentos provocados pelas chuvas de verão, o que resulta em graves perdas sociais e muitos desabrigados ${ }^{5}$. No ano de 2011, uma catástrofe assolou parte do seu território e de outros 19 municípios da Região Serrana, o que resultou em918 mortes, mas estima-se que esse número é bem superior ${ }^{6}$. Por sua vez, o governo municipal, rendendo-se ao PMCMV como forma de política habitacional, justificou sua inércia em produzir moradia com a verba federal disponibilizada sob o argumento de que faltavam terrenos adequados para a construção de moradias no formato do programa. Afinal, os empresários negavam-se a empreender na cidade, diante do alto custo para preparar os terrenos (HAUBRICH, 2015). Isso revela como o poder municipal comporta-se de forma dependente diante do governo federal e suas fórmulas prontas das políticas públicas.

\footnotetext{
${ }^{5}$ Petrópolis se desmancha: com obras paradas, município tem 27 mortos e mais 366 famílias desabrigadas. Desde a noite de domingo, já são 498 as ocorrências registradas pela Defesa Civil. Há dois anos, 876 famílias vivem do aluguel social na cidade. 0 total de mortos desde a noite de domingo, em Petrópolis, chegou a 27 na tarde desta terça-feira. Ainda há cerca de 10 desaparecidos que, de acordo com equipes da Defesa Civil, podem ser de pessoas que ficaram sob os escombros em uma das 21 áreas desmoronadas. Em meio a medidas emergenciais, busca de corpos e anúncios de liberação de verba, a população de Petrópolis assiste, mais uma vez, ao triste espetáculo da cidade que se desmancha: mais encostas rolaram, mais casas estão sendo interditadas e até o momento não houve entrega - ou construção - de uma casa sequer, entre os 112 apartamentos prometidos pelos governos federal e estadual. Desde a chuva de janeiro de 2011, 876 famílias recebem aluguel social - mas dentro de pouco tempo não haverá sequer o que alugar, dado o ritmo do trabalho de reconstrução.já são 498 as ocorrências registradas pela Defesa Civil. O local mais atingido pelas chuvas, o bairro Quitandinha, recebeu em 36 horas um volume de chuva equivalente a 499 milímetros, quase o dobro do esperado para todo o mês de março, que era de 270 milímetros. Os números e estimativas não cabem mais na realidade da Região Serrana do Rio. Desde a madrugada de 12 de janeiro de 2011, Nova Friburgo já teve ruas alagadas diversas vezes; Teresópolis teve novas mortes, em 1ª de maio de 2012; e, agora, Petrópolis revive a tragédia. RITTO, Cecília. Petrópolis se desmancha: com obras paradas, município tem 27 mortos e mais 366 famílias desabrigadas. Veja.com, Rio de Janeiro,19 mar. 2013. Disponível em:

http://veja.abril.com.br/brasil/petropolis-se-desmancha-com-obras-paradas-municipio-tem-27-mortos-e-mais-366-familiasdesabrigadas/

${ }^{6}$ № de vítimas em tragédia no RJ pode ser 10 vezes maior, dizem entidades. Lista oficial diz que 918 morreram em Petrópolis, Teresópolis e Friburgo.Enchentes de 2011 fizeram cerca de 10 mil vítimas, segundo associações.A suposta subnotificação de mortes foi identificada através de relatos de pessoas que moravam nas áreas atingidas e que não conseguiram oficializar a perda de parentes.

Divergência de números. Além do relato de parentes, as entidades levam em conta a divergência entre o número computado de mortos em determinadas localidades e a quantidade de "relógios de luz" que havia nestes locais, segundo a própria concessionária de energia elétrica, a Ampla."Acreditamos que aproximadamente 10 mil pessoas foram afetadas. Haver pouco mais de mil [mortos e desaparecidos], como é divulgado, é um número irreal pela proporção da tragédia". CANEJO, Andressa. № de vítimas em tragédia no RJ pode ser 10 vezes maior, dizem entidades. Portal G1. 10 de ago. de 2015. Diponível em: http://g1.globo.com/rj/regiao-serrana/noticia/2015/08/entidades-apontam-subnotificacao-de-vitimas-datragedia-de-2011-na-serra.html.
} 
Um cadastro territorial bem elaborado detém em seus registros uma grande base de dados, e com isso, instrumentaliza o planejamento da política urbana e facilita o controle do território municipal, além de contribuir com a elaboração e gestão de políticas públicas. Essa dinâmica fortalece o protagonismo do poder municipal na mediação de projetos habitacionais com a iniciativa privada, uma vez que, por meio da gestão dos instrumentos disponíveis o município pode formar seu próprio "banco de terras"oferecendo aos incorporadores terrenos mais centrais para moradia social.

Da mesma forma, o fundo municipal para habitação de interesse social poderia ser alimentado pela gestão social do seu território por meio da aquisição de terrenos e a produção de moradia. Além disso, o fortalecimento da autonomia municipal nesta política possibilitaria o rompimento da lógica de concentração da produção habitacional em poucas empresas, prática mercantil que impõe a padronização de preços no mercado imobiliário visando o aumento da rentabilidade do negócio. Nessas condições, a diminuição da mercantilização da política habitacional de interesse social contribuiria para maior diversificação da produção, assim como do barateamento de seus custos (CARDOSO; ARAGÃO, 2013).

Essa concentração de mercado pode ser exemplificada no caso do Rio de Janeiro, onde apenas dez empresas foram identificadas como responsáveis por $65 \%$ da produção habitacional (CARDOSO; ARAGÃO, 2013), e ainda, no caso de Fortaleza, em que apenas duas construtoras detêm 70\% desse mercado. Segundo Rufino (2013), as grandes empresas de construção nacionais e locais tendem a associar-se, criando Sociedades de Propósitos Específicos para gerenciar os empreendimentos. Isso fortalece ainda mais a concentração do mercado e, assim, as soluções em grande escala a que já fizemos referência.

A adaptação de projetos habitacionais à realidade local com custos reduzidos é viável, como sugere o estudo de Frajndlich (2012). Este ocorreu no Município de Caruaru (PE), onde o escritório Jirau Arquitetura elaborou um projeto específico para a construção de um bairro popular ${ }^{7}$ utilizando

\footnotetext{
${ }^{7}$ Bairro habitacional desenhado pela Jirau Arquitetura em Caruaru, Pernambuco, cria nova referência de casas econômicas na cidade.O projeto optou por paredes altas e coberturas inclinadas formando uma sucessão de cores. As casas foram
} 
conceitos construtivos da tradicional técnica local, além de uma boa leitura do terreno, de suas condicionantes de implantação e da criação de uma nova fachada. Esse conjunto de decisões resultou em um empreendimento personalizado que rompe com a lógica repetitiva da habitação social. 0 exemplo citado sugere a possibilidade de que o poder público exerça o controle efetivo do planejamento urbano, promovendo uma política habitacional coerente e estimulando projetos que se adaptem às condições e realidades locais. Um compromisso municipal dessa natureza com a gestão social de seu território daria maior efetividade à política local de habitação de interesse social.

\section{Pesquisa de Campo: mapeando imóveis ociosos em áreas centrais de Petrópolis}

Petrópolis elaborou seu diagnóstico sobre a situação de moradia no Primeiro Distrito do Município, mas não fez referência à atualização de cadastro territorial nem à inclusão de imóveis ociosos na estrutura da sua política habitacional. Observa-se que um cadastro bem elaborado identifica as várias categorias de ociosidade imobiliária do tecido urbano, isto é, indica, de acordo com a legislação local, os imóveis classificados como terrenos vagos, edificados, mas desocupados e subutilizados.

Nesse contexto, percebe-se que o poder público municipal ao elaborar o PLHIS mostra desconhecimento no potencial fundiário da própria cidade. Isso pode ser observado pela falta de mapeamento da área urbana, e também pela listagem de terrenos apresentados para compor a política habitacional do Município, vinte e dois ao todo, ${ }^{8}$ distribuídos por todos os seus distritos. Nota-se que

implementadas de modo escalonado no terreno acidentado permitindo ao observador que sinta o movimento das paredes e o volume colorido das caixas d'água ao caminhar pela vila. As residências foram construídas em forma de "S" com dois dormitórios, sala e cozinha. O formato desalinhado traduz-se como uma estratégia para controlar a funcionalidade da planta e a linha estética original do projeto diante das possíveis alterações que os moradores geralmente fazem. A proposta do projeto comporta a abertura de um quarto extra que se abriria para o quintal, assim as alterações não descaracterizam a fachada nem interferem na alvenaria e cobertura do conjunto.

${ }^{8}$ Estrada União e Indústria, 12.089, Pedro do Rio $\left(15.000 \mathrm{~m}^{2}\right)$; Fazenda San Joaquim, gleba 05, Vale do Cuiabá $\left(10.000 \mathrm{~m}^{2}\right)$; Estrada João de Oliveira Botelho, Itaipava-Santa Mônica (10.000m²); Estrada Caetitu, s/n, bairro Caetitu $\left(15.000 \mathrm{~m}^{2}\right)$; Estrada Luiz Gomes da Silva, 893, Caetitu (15.000m²); Estrada Philuvio Cerqueira, Itaipava (10.00m²); Rua Henrique Paixão, morro do Calango, bairro Itamarati (2000m²); BR 040, Pedro do Rio (50.000m²); Estrada Philuvio Cerqueira, 2016, Itaipava (20.000m²), Estrada Ministro Salgado Filho, Vale do Cuiabá (20.000m²); Estrada Caetitu, Eduardo Silverio, (8.000m²); Rua João Xavier, 1015, bairro Duarte da Silveira (10.000m²); Rua Ângelo João Brandt, Quarteirão Italiano $\left(48.000 \mathrm{~m}^{2}\right)$; Estrada do Caetitu/Vale dos Esquilos, bairro Retiro (40.000m²); Pista de Esqui, bairro Floresta $\left(15.000 \mathrm{~m}^{2}\right)$; Estrada Independência , clínica Pedras Brancas (25.000m²); Rua Vassouras, quadra 83, bairro Quitandinha $\left(6.000 \mathrm{~m}^{2}\right)$; Rua Quissamã, s/n, depósito da Seobras, bairro Quissamã (6.000m²); Rua Quissamã, 
essa lista não inclui os imóveis ociosos identificados pela pesquisa de campo, o que leva à possibilidade de existir mais terra urbana compatível com a gestão social da valorização fundiária.

As palavras inscritas no PLHIS do Município de Petrópolis (2012, p. 154) confirmam o desconhecimento do seu potencial fundiário ao afirmar que:

a população, por sua vez, também afirmou conhecer terrenos vazios que poderão ser utilizados para a provisão de novas unidades habitacionais de interesse social. A Prefeitura deverá aprofundar as informações sobre os terrenos vazios aptos no intuito de reservá-los para futuros empreendimentos de HIS.

Diante disso, observa-se que o poder municipal atua em função de um plano incompleto, por desconhecer o próprio tecido urbano. Cabe ainda destacar que os terrenos selecionados pela listagem seguem o perfil adotado pela lógica do mercado de construção, isto é, grandes terras afastadas dos centros para sediar conjuntos habitacionais. Tal abordagem é reveladora de um comportamento que impede uma gestão social integrada às potencialidades locais ao preferir selecionar de forma aleatória terrenos que atendam ao planejamento do mercado.

Ao tratar dessa forma a política habitacional, o Município não correlaciona a realidade do déficit habitacional com a sua competência sobre a gestão de seu território para fins de moradia. Isso seria possível com a elaboração de um cadastro territorial atualizado de toda área urbana, o que permitiria selecionar terrenos para habitação de acordo com o déficit de cada região, a fim de alocar os moradores em local próximo à sua morada de origem. Essa correspondência de fatores facilitaria o alcance da inclusão socioespacial da cidade e o reconhecimento da população empobrecida.

Na busca de escolher terrenos que atendam ao perfil do mercado, o poder municipal desconsidera outros tantos que podem compor uma política habitacional diversa do padrão do mercado imobiliário, como será adiante demonstrado pela pesquisa de campo realizada em três bairros de Petrópolis.

floricultura, bairro Quissamã $\left(8.000 \mathrm{~m}^{2}\right)$; Estrada Almeida Amado, bairro Caxambú $\left(20.000 \mathrm{~m}^{2}\right)$; Alberto de Oliveira, bairro Mosela $\left(8.000 \mathrm{~m}^{2}\right)$. (PLHIS do Município de Petrópolis, 2012, p. 154.) 
Ao render-se à produção habitacional planejada pelo mercado, a administração municipal confirma o processo de periferização da moradia e o crescimento extensivo da cidade. Esse ciclo vicioso exemplifica-se pelos dois terrenos desapropriados pela Prefeitura para a construção de conjuntos habitacionais do PMCMV para a faixa de renda até $\mathrm{R} \$ 1.600,00$.

O primeiro terreno encontra-se localizado na Estada do Caetitu, uma área distante do $2^{0}$ distrito, sem infraestrutura e equipamentos públicos básicos, mas que atende ao padrão das construtoras por possuir uma superfície de $15.000 \mathrm{~m}^{2}$ e contar com o apoio do poder público para levar a infraestrutura necessária aos futuros moradores ${ }^{9}$. Essa iniciativa reproduz com nitidez o antigo processo de periferização e crescimento horizontal das cidades do antigo Sistema BNH, o que sugere a urgência em romper com essa lógica ${ }^{10}$.

Na mesma linha de atuação, encontra-se o segundo empreendimento, também do PMCMV. Este se localiza na Rua Vicenzo Rivetti, em área distante dos centros urbanos, mas relativamente próxima ao projeto citado acima, o que possibilita o aproveitamento da infraestrutura aos dois empreendimentos. Cabe ressaltar que a contrapartida da Prefeitura com relação a esse conjunto habitacional é a abertura

\footnotetext{
${ }^{9}$ Prefeito vistoria obra de pavimentação da Estrada do Caetitu. O prefeito Rubens Bomtempo vistoriou nesta semana as obras de pavimentação e drenagem da Estrada Luiz Gomes da Silva. As intervenções vão permitir a ligação entre os bairros Carangola e Corrêas, abrindo uma rota alternativa entre as duas importantes regiões do município. Ambas receberão novos conjuntos habitacionais. $O$ investimento é superior a $\mathrm{R} \$ 1,696$ milhão e faz parte do convênio com o governo do Estado, por meio do Programa Somando Forças. "Queremos aproximar esses dois conjuntos e agregar valor aos bairros não só com as melhorias em infraestrutura, como também com a instalação de novos equipamentos públicos. A ideia é que a escola, o centro de educação infantil, o posto de saúde e o centro de referência em assistência social que serão construídos pela Prefeitura atendam de forma integrada as duas comunidades", disse o prefeito. PETRÓPOLIS. Prefeitura Municipal. Prefeito vistoria obra de pavimentação da Estrada do Caetitu. Petrópolis, 14 abril 2014. Disponível em: http://petropolisnews.com.br/?p=3626.

${ }^{10}$ Sistema estruturado a partir da construção de conjuntos habitacionaisnos pontos mais distantes da periferia, criando verdadeiros bairros dormitório, com o pretexto de que aqueles eram os únicos lugares que ofereciam, ao mesmo tempo, terra barata e adequada à produção em larga escala. Esta lógica leva ao forçado crescimento horizontal das cidades representado tanto pelos investimentos em infraestrutura básica para alcançar tais conglomerados, quanto pelo natural desenvolvimento das dinâmicas urbanas advindas da população transferida. Nas palavras de Bonduki (2000,pg 21) "caracterizam-se, em geral, pela monotonia de sua arquitetura; pela ausência de relação com o entorno; por sua localização periférica, estendendo horizontalmente as cidades; pela despreocupação com a qualidade dos projetos e com o meio físico, resultando na depredação ambiental [...]"
} 
de uma rua ligando o novo conjunto habitacional à localidade do Caetitu, além da preparação do terreno com terraplanagem e fundação $0^{11}$.

Essas iniciativas evidenciam que a pouca iniciativa municipal para executar projetos habitacionais não está vinculada, necessariamente, à ausência de recursos financeiros: afinal os custos em infraestrutura e preparação do terreno são altos. Portanto, parece possível à Prefeitura implementar políticas de habitação próprias, geradas a partir uma gestão social da valorização fundiária. Essa autonomia em relação ao mercado imobiliário poderia romper com o paradigma do crescimento urbano extensivo e permitir o maior adensamento de áreas centrais.

A força que o mercado da construção exerce sobre o controle e a produção da habitação reflete-se na padronização urbanística, periferização da moradia, protagonismo na política habitacional e direcionamento do crescimento das cidades. O objetivo de todas essas ações é produzir com rentabilidade unidades habitacionais. Nestas condições, não causa estranheza verificar, com Lucia Schimbo (2010), que os empreendedores preferem produzir moradias para as faixas superiores de renda, dado que geram maior rentabilidade, motivo pelo qual evitam aquela faixa onde se concentra 0 maior déficit habitacional, voltada para aqueles adquirentes com renda inferior aos $\mathrm{R} \$ 1.600,00$.

Essa realidade não é diferente no Município de Petrópolis, já que, dos oito empreendimentos do PMCMV planejados para a cidade, seis contemplam a faixa de renda 02 do Programa ${ }^{12}$. Os dois

\footnotetext{
${ }^{11}$ Bomtempo vistoria andamento das obras do novo Conjunto Habitacional do VicenzoRivetti.O prefeito Rubens Bomtempo vistoriou nesta sexta-feira as obras de construção das 778 unidades habitacionais do Programa Minha Casa Minha Vida que serão erguidas no VicenzoRivetti, no bairro Carangola. No terreno, o serviço de terraplanagem já está sendo concluído e aexpectativa é que a partir do mês de junho seja iniciada a fase de fundação. 0 investimento é de R $\$ 63$ milhões. A obra está sendo executada pela Construtora Andrade Almeida e durante a visita, acompanhado pelos secretários de Habitação, Rodrigo Seabra e o de Obras, Aldir Cony, Bomtempo discutiu a contrapartida do município. Um dos pontos foi o terreno a ser utilizado para a abertura de uma rua ligando o novo conjunto habitacional a localidade do Caetitu, onde também existe aprevisão de implantação do Programa Minha Casa Minha Vida. "São medidas importantes, pois garantirão toda a infraestrutura necessária para a população. Fazer um pouco mais pelo povo é o que justifica o nosso terceiro mandato. Somos um governo popular e que tem como prioridade atender a quem está por último na fila”, ressaltou. Além de Centro de Educação Infantil, uma nova escola com capacidade para atender quase mil alunos, um Posto de Saúde e um Centro de Referência em Assistência Social (Cras) também serão implantados no local.PETRÓPOLIS. Prefeitura Municipal. Bomtempo vistoria andamento das obras do novo Conjunto Habitacional do VicenzoRivetti. Petrópolis, 18 maio 2014. Disponível em:<http://www.petropolis.rj.gov.br/pmp/index.php/imprensa/noticias/item/2247-bomtempo-vistoria-andamento-dasobras-do-novo-conjunto-habitacional-do-vicenzo-rivetti.html>. Acesso em: 17 jun. 2014.
} 
projetos de habitação social que conferem moradia para a faixa 01 localizam-se na Estrada do Caetitu e na Rua VicenzoRivetti como já mencionado.

Esta preferência pelas faixas de maior renda também afeta a política habitacional petropolitana, pois corre-se o risco de perder um dos empreendimentos destinados à faixa 01 do programa. De acordo com uma publicação da imprensa local, ${ }^{13}$ desde novembro de 2015 tramita, na Câmara dos Vereadores, um projeto de lei que determina a desafetação do terreno da Estrada do Caetitu, para que este passe a sediar um conjunto habitacional destinado à faixa 02 do PMCMV. 0 argumento utilizado pelo legislativo municipal está respaldado no fato de que a desapropriação tem mais de dois anos e as obras ainda não foram iniciadas (BARROSO, 2015).

Essas dificuldades, ligadas à opção de produzir moradia por meio de um formato único, leva ao questionamento da manutenção dessa escolha. Afinal, apesar do PMCMV guardar diferenças em relação ao Sistema BNH, suas semelhanças também se refletem diante do padrão de produção, localização na periferia urbana e o não alcance da população de baixa renda. Mudar tal orientação e definir uma gestão social da valorização fundiária, possibilitaria construir uma política habitacional coerente às condições locais de cada cidade, o que poderia levar a execução de projetos alternativos de habitação social de menor monta. Dessa forma, além de desvincular a produção de moradia do formato de grandes condomínios, também seria facilitada a administração e a conservação das moradias pelos moradores.

${ }^{12}$ O PMCMV vai garantir mais 840 apartamentos em Petrópolis, através de três empreendimentos: um no Bingen, outro no Morin e em Pedro do Rio. O Programa é voltado para famílias com renda bruta até $\mathrm{R} \$ 1,6$ mil e R $\$ 3,275$ mil. A prefeitura já recebeu os projetos e decretou os terrenos área de especial interesse social, abrindo caminho para que sejam realizados pelo programa. "Estes projetos somam-se a outros três, já licenciados pelo Município. Estamos avançando nesta questão", frisou o prefeito, fazendo referência aos empreendimentos Cenário de Monet, Bosque de Montreal e Palmeiras do Prado, que receberam incentivos fiscais da prefeitura e garantirão a construção de 814 novas unidades habitacionais na região de Correas.Equipe acontece Petrópolis. Bingen, Pedro do Rio e Morin receberão empreendimentos do Minha casa, Minha vida.Portal Acontece Petrópolis. Petrópolis, 03 nov. 2015. Disponível em:

http://www.aconteceempetropolis.com.br/2015/11/03/bingen-pedro-do-rio-e-morin-receberao-empreendimentos-do-minhacasa-minha-vida/

${ }^{13}$ Vereadores discordam sobre Minha Casa Minha Vida.Tramita na Câmara há pouco mais de 15 dias um projeto de lei na Câmara para desafetação de um terreno destinado ao Minha Casa Minha Vida (MCMV) faixa 1.0 objetivo é passar uma área no Caititu para a faixa 2 do programa de construção moradias populares. O motivo é que as obras não tiveram início mesmo após dois anos após a desapropriação do local.BARROSO, Romulo. Vereadores discordam sobre Minha Casa Minha Vida. Jornal Diário de Petrópolis. Petrópolis, 30 nov. 2015. Disponível em: <http://diariodepetropolis.com.br/integra/vereadoresdiscordam-sobre-minha-casa-minha-vida-76728>. Acesso em: 01 dez. 2015. 
O Município de Petrópolis possui um déficit habitacional quantitativo de 11.828 moradias (Tabela 2 Resumo do déficit habitacional), sendo que 5.213 destas localizam-se em assentamentos precários, e dentre estas, 2.994 estão no Primeiro Distrito. Portanto, o PLHIS de Petrópolis dispõe que o déficit habitacional em assentamentos precários no $1^{0}$ Distrito é de 2.994 moradias, além disso, estabelece uma contrapartida de $362.625 \mathrm{~m}^{2}$ em terra urbana para resolver a demanda de domicílios nos assentamentos dessa área (PETRÓPOLIS, 2012, p. 144, 145, 153).

A listagem apresentada pelo PLHIS indica vinte e dois terrenos, distribuídos em todo o Município, adaptáveis ao perfil do mercado com seus grandes conjuntos habitacionais. Dentre esses terrenos, dez $^{14}$ estão localizados no Primeiro Distrito, medindo o total de $186.000 \mathrm{~m}^{2}$. Sendo assim, faltam $192.625 \mathrm{~m}^{2}$ de terra urbana para zerar o déficit habitacional de 2.994 moradias em assentamentos precários localizados no $1^{0}$ Distrito. Cabe lembrar que o déficit real de moradias nos assentamentos precários do primeiro distrito é superior ao apresentado pelo PLHIS quando consideradas as residências em situação de risco naquela área.

\begin{tabular}{ll}
\hline Déficit assentamentos precários & 2.994 \\
Moradias em situação de risco & 7.076 \\
Demanda de terras p/ assentamentos prec. & $362.625 \mathrm{~m}^{2}$ \\
Disponibilidade de terras p/ assent. prec. & $186.000 \mathrm{~m}^{2}$ \\
Carência de terras p/ assentamentos prec. & $192.625 \mathrm{~m}^{2}$
\end{tabular}

Tabela 3. déficit habitacional e demanda de terras no $1^{\circ}$ Distrito. Fonte: PLHIS. 2012.

Diante desse quadro, nota-se a imprescindibilidade de o poder municipal selecionar terra urbana apta a compor a sua política habitacional, o que leva ao dever de conhecer a totalidade do seu tecido urbano e incluir os imóveis ociosos como instrumentos de gestão urbana.

\footnotetext{
${ }^{14}$ Rua João Xavier, 1015, bairro Duarte da Silveira $\left(10.000 \mathrm{~m}^{2}\right)$; Rua Ângelo João Brandt, Quarteirão Italiano $\left(48.000 \mathrm{~m}^{2}\right)$; Estrada do Caetitu/Vale dos Esquilos, bairro Retiro $\left(40.000 \mathrm{~m}^{2}\right)$; Pista de Esqui, bairro Floresta $\left(15.000 \mathrm{~m}^{2}\right)$; Estrada Independência , clínica Pedras Brancas $\left(25.000 \mathrm{~m}^{2}\right) ; \quad$ Rua Vassouras, quadra 83, bairro Quitandinha $\left(6.000 \mathrm{~m}^{2}\right)$; Rua Quissamã, s/n, depósito da Seobras, bairro Quissamã $\left(6.000 \mathrm{~m}^{2}\right)$; Rua Quissamã, floricultura, bairro Quissamã $\left(8.000 \mathrm{~m}^{2}\right) ; \quad$ Estrada Almeida Amado, bairro Caxambú $\left(20.000 \mathrm{~m}^{2}\right) ; \quad$ Alberto de Oliveira, bairro Mosela $\left(8.000 \mathrm{~m}^{2}\right)$. (PLHIS do Município de Petrópolis, 2012, p. 154).
} 
A partir desse contexto, a pesquisa de campo procurou identificar vazios urbanos classificados como terrenos vagos. A opção por essa categoria de imóvel ocioso explica-se pela dificuldade em identificar e comprovar, documentalmente, os imóveis edificados, mas desocupados e aqueles subutilizados, o que exigiria a máquina do poder público como elemento de apoio. Além disso, a abrangência da pesquisa tornar-se-ia de tal forma complexa que ultrapassaria os limites possíveis a uma investigação acadêmica.

A pesquisa foi realizada nos bairros Quitandinha, Bingen e Duarte da Silveira por situarem-se no Primeiro Distrito de Petrópolis onde há a maior concentração demográfica, circulação de riquezas e demandas de trabalho do Município, e também por localizarem-se em áreas centrais da cidade dotadas com equipamentos públicos, infraestrutura e serviços básicos à população.

\section{Metodologia da pesquisa de campo}

O trabalho de campo iniciou-se nas ruas dos bairros selecionados a partir da identificação visual de terrenos vagos. Constatando-se tal ociosidade passava-se a anotação do número, lote ou quadra do imóvel se existisse, e ainda, de seus respectivos confrontantes para servir como material inicial à coleta de dados, e posteriormente como referência à localização dos imóveis nos arquivos municipais.

Após a seleção in loco foi realizada uma busca nos arquivos dos órgãos públicos a fim de encontrar registros que confirmem a ociosidade antes identificada. Os documentos examinados fazem parte dos arquivos municipais da Secretaria de Fazenda, do Cadastro Imobiliário e da Assessoria de Cadastro e Edificação (ACADE), e consubstanciam-se em desenhos isolados dos locais pesquisados (croquis), mapa da Companhia Terrenos Quitandinha S.A., formulários de cadastro e plantas de situação.

Após muita pesquisa foram localizados os imóveis vagos nos arquivos além de outros encontrados nos próprios registros municipais. A partir da identificação dos terrenos dentro dos arquivos foi possível levantar o espelho do IPTU de cada um deles contendo a informação da metragem e de que são 
terrenos sem uso no solo urbano. Dessa forma, foi confrontada a realidade fática com os registros da prefeitura.

No decorrer da pesquisa foi observada a precariedade do cadastro municipal que opera com arquivos físicos compostos por formulários e desenhos antigos e amarelados cuja atualização é igualmente precária. Muitas áreas da cidade não possuem mapas de identificação territorial com lotes e quadras definidas a fim de facilitar a administração e fiscalização do solo urbano. Na realidade, apenas o bairro Quitandinha possui um mapeamento definido do seu solo com o respectivo plano geral de loteamento, elaborado em 1950, pela Companhia Terrenos Quitandinha S.A.

Dentre os imóveis que compõem o tecido urbano do Primeiro Distrito foram catalogados sessenta e três terrenos vagos, ao todo. Destes, trinta e nove estão localizados no bairro Quitandinha e vinte e quatro nos bairros Duarte da Silveira e Bingen. Esses terrenos somam a metragem de $216.782,352 \mathrm{~m}^{2}$, representando $60 \%$ dos $362.625 \mathrm{~m}^{2}$ de terra urbana necessária para eliminar o déficit habitacional dos assentamentos precários do primeiro distrito, de acordo com o PLHIS do Município.

\begin{tabular}{lll}
\hline BAIRRO & № DE TERRENOS & METRAGEM \\
\hline Quitandinha & 39 & $43.676 \mathrm{~m}^{2}$ \\
Duarte da Silveira/Bingen & 24 & $173.106,352 \mathrm{~m}^{2}$ \\
\hline TOTAL & 63 & $216.782,352 \mathrm{~m}^{2}$ \\
\hline
\end{tabular}

Tabela 4. Distribuição e metragem dos imóveis vagos nos bairros pesquisados. Fonte: pesquisa de campo e Prefeitura Municipal de Petrópolis.

Dos terrenos pesquisados, constata-se que trinta e um deles estão com o IPTU em atraso há mais de três anos. Além disso, foi detectado que dois imóveis inicialmente considerados como vagos são, na realidade, áreas industriais que possuem grandes terrenos subutilizados. Essa realidade foi constatada após a coleta de dados nos registros do cadastro imobiliário. Além dessas, foi identificada uma área utilizada para estacionar poucos carros, que também poderia ser classificada como subutilizada, 
localizada ao lado de um terreno vago, o que permitiria um planejamento em conjunto para os dois terrenos.

Cabe acrescentar que vários lotes identificados na pesquisa são confrontantes uns dos outros, o que significaria a existência de grandes terrenos disponíveis, o que muito contribuiria para o plano habitacional da gestão municipal.

\begin{tabular}{llll}
\hline BAIRRO & № DE TERRENOS & METRAGEM & EDIFICAÇÃO \\
\hline Quitandinha & 01 & $566 \mathrm{~m}^{2}$ & $179,00 \mathrm{~m}^{2}$ \\
Duarte da Silveira/Bingen & 02 & $21.873,726 \mathrm{~m}^{2}$ & $2.506 \mathrm{~m}^{2}$ \\
& & $16.490 \mathrm{~m}^{2}$ & $809 \mathrm{~m}^{2}$ \\
\hline TOTAL & 03 & $38.363,726 \mathrm{~m}^{2}$ & $3.315 \mathrm{~m}^{2}$
\end{tabular}

Tabela 4. Identificação e metragem de terrenos subutilizados. Fonte: pesquisa de campo e Prefeitura Municipal de Petrópolis.

Observa-se, pelos dados apresentados, que o rastreamento de imóveis vagos em apenas três bairros do Primeiro Distrito do Município representa a maior parte da terra urbana necessária para a eliminação do seu déficit habitacional em assentamentos precários. Isso leva à indagação de quantos imóveis vagos, não utilizados e subutilizados existem na área urbana de toda a cidade. Um cadastro territorial atualizado certamente poderia constituir-se num instrumento que potencializaria a gestão social da valorização fundiária que visasse a moradia social como vetor principal.

\section{CONCLUSÕES}

Um estudo preliminar de campo, sem contar com mais recursos do que o empenho acadêmico, indicou a existência de terras urbanas dotadas de adequada infraestrutura urbana, mas que estão ociosas, em flagrante desrespeito à Constituição da República que determina nos artigos $5^{\circ}$, inciso XXIII, e 170, inciso III que a propriedade deve cumprir sua função social.

O Programa Minha Casa Minha Vida tem a importante virtude de mobilizar valores significativos e inéditos para subsidiar a moradia social. Apresenta, contudo, muitas deficiências, algumas das quais 
foram destacadas nesse artigo. Mas nunca é demais lembrar que se trata de um programa formulado e financiado pelo governo federal. Os governos estaduais e, principalmente, os municipais precisam atuar na política habitacional, que, como as demais políticas sociais, são de responsabilidade das três esferas de governo.

A política urbana, no entanto, está expressamente normatizada como de competência municipal. Considerando que a moradia é parte da política urbana, os municípios deveriam atuar no sentido de conciliar o programa federal às particularidades do seu território. Não deveriam recepcionar o PMCMV como se sua atuação se restringisse apenas a aderir ao programa.

O estudo ora apresentado sugere a necessidade de atuação mais propositiva dos governos municipais, caso sejam exploradas as possibilidades que um cadastro territorial atualizado lhes ofereceriam. Afinal, identificamos terrenos ociosos, correspondendo a um total de aproximadamente $60 \%$ de solo urbano necessário para enfrentar o déficit habitacional naquela localidade.

\section{REFERÊNCIAS}

BONDUKI, Nabil. Do projeto moradia ao programa minha casa minha vida. TD. Teoria e Debate, São Paulo, v. 82 , p. 8 14, maio 2009.

BONDUKI, Nabil. Habitar São Paulo: reflexões sobre a gestão urbana. São Paulo: Estação Liberdade, 2000.167 p.

BRASIL. Portaria Ministerial n. 511, de 07 de dezembro de 2009. Institui diretrizes para a criação, instituição e atualização do Cadastro Territorial Multifinalitário (CTM) nos municípios brasileiros. Diário Oficial da União, 08 de dezembro de 2009.

BARroso, Romulo. Vereadores discordam sobre Minha Casa Minha Vida. Jornal Diário de Petrópolis. Petrópolis, 30 nov. 2015. Disponível em: <http://diariodepetropolis.com.br/integra/vereadores-discordam-sobre-minha-casa-minha-vida$76728>$. Acesso em: 01 dez. 2015.

BRASIL. Constituição (1988). Constituição brasileira, 1988. Texto constitucional de 5 de outubro de 1988. Brasília: Senado Federal, Centro Gráfico, 292 p.

CANEJO, Andressa. № de vítimas em tragédia no RJ pode ser 10 vezes maior, dizem entidades. Portal G1. 10 de ago. de 2015. Diponível em: http://g1.globo.com/rj/regiao-serrana/noticia/2015/08/entidades-apontam-subnotificacao-de-vitimasda-tragedia-de-2011-na-serra.html.

CARDoso, A. Lúcio; ARAGÃO, T. Amorim. Do fim do BNH ao Programa Minha Casa Minha Vida: 25 anos da política habitacional no Brasil. In: Cardoso, A. L. (Org.). O Programa Minha Casa Minha Vida e seus efeitos territoriais. Rio de Janeiro: Letra Capital, 2013. p. 17-65. 
EQUIPE ACONTECE PETRÓPOLIS. Bingen, Pedro do Rio e Morin receberão empreendimentos do Minha casa, Minha vida. Portal Acontece Petrópolis. Petrópolis, 03 nov. $2015 . \quad$ Disponível em: http://www.aconteceempetropolis.com.br/2015/11/03/bingen-pedro-do-rio-e-morin-receberao-empreendimentos-do-minhacasa-minha-vida/

FRAJNDLICH, Rafael Urano. Jirau Arquitetura desenha nova proposta de habitação social para o Programa Minha Casa Minha vida em Caruaru, PE. aU - Arquitetura e Urbanismo, [S. 1.], ano 27, n. 224, 2012. Disponível em: $<\underline{\text { http://au.pini.com.br/arquitetura-urbanismo/224/modernas-referencias-bairro-habitacional-desenhado-pela-jirau- }}$ arquitetura-em-273187-1.aspx $>$. Acesso em: 14 set. 2014.

HAUBRICH, Gabriela. Falta oferta de moradias populares em Petrópolis. Verbas do "Minha Casa, Minha Vida" não atraem empreiteiras devido ao alto custo da construção na cidade. Jornal Diário de Petrópolis, Petrópolis, 15 jun. 2015. Disponível em: <http://diariodepetropolis.com.br/Integra/falta-oferta-de-moradias-populares-em-petropolis-66954>

PETRÓPOLIS. PLHIS - Plano Local de Habitação de Interesse social. Petrópolis: SEHAB. 2012.

PETRÓPOLIS. Prefeitura Municipal. Bomtempo vistoria andamento das obras do novo Conjunto Habitacional do

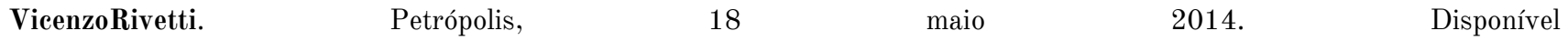
em:<http://www.petropolis.rj.gov.br/pmp/index.php/imprensa/noticias/item/2247-bomtempo-vistoria-andamento-dasobras-do-novo-conjunto-habitacional-do-vicenzo-rivetti.html>. Acesso em: 17 jun. 2014.

PETRÓPOLIS. Prefeitura Municipal. Prefeito vistoria obra de pavimentação da Estrada do Caetitu. Petrópolis, 14 abril 2014. Disponível em: http://petropolisnews.com.br/?p=3626.

RITTO, Cecília. Petrópolis se desmancha: com obras paradas, município tem 27 mortos e mais 366 famílias desabrigadas. Veja. Com., Rio de Janeiro,19 mar. 2013. Disponível em: http://veja.abril.com.br/brasil/petropolis-se-desmancha-comobras-paradas-municipio-tem-27-mortos-e-mais-366-familias-desabrigadas/

ROLNIK, Raquel. Arquitetura: direito de todos. Jornal Folha de São Paulo, São Paulo, 05 out. 2015. Disponível em: <http://www1.folha.uol.com.br/colunas/raquelrolnik/2015/10/1690164-arquitetura-direito-de-todos.shtml>. Acesso em: 22 nov. 2015.

SHIMBO, Lúcia Zanin. Habitação social, habitação de mercado: a confluência entre Estado, empresas construtoras e capital financeiro. 2010. 363 f. Tese (Doutorado em Teoria e História da Arquitetura e do Urbanismo) - Escola de Engenharia de São Carlos, Universidade de São Paulo, São Carlos, 2010. Disponível em: <http://www.teses.usp.br/teses/disponiveis/18/18142/tde-04082010-100137/>. Acesso em: 10 jun. 2014. 